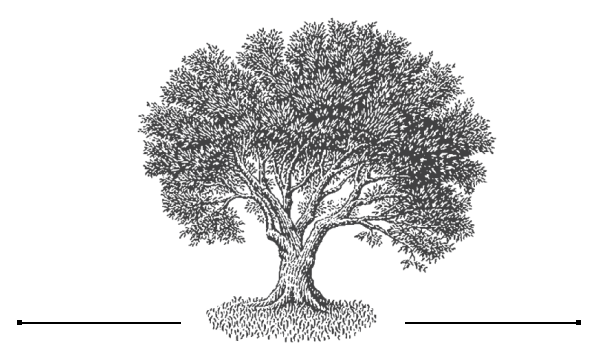

\section{Образ Византии}

в романе

В. А. Каверина “Перед зеркалом"

\section{Ася Вадимовна Кулакова}

Национальный исследовательский университет "Высшая школа экономики"

Москва, Россия
The Image of Byzantium in the Novel

In Front of the Mirror by Veniamin Kaverin

\title{
Peзюмe
}

Настоящая статья посвящена исследованию образа Византии в романе В. А. Каверина "Перед зеркалом", в основу которого легла многолетняя переписка между советским математиком Павлом Безсоновым и художницей-эмигранткой Аидией Никаноровой. Отмечается близость христианской метафорики и религиозной рефлексии, которые Каверин приписывает художнице 20-х годов, образному и идейному ряду, характерному для эпохи самого Каверина и его современников. Сама идея обращения к Византии Кавериным не выдумана: в действительности реальная Никанорова неоднократно возвращается к византийской теме в своих письмах, однако само представление о Византии и родь, отведенная ей, в реальной переписке кардинально отдичается от того, что читатель находит в романе. Основываясь на сравнении комплекса идей и метафор, связанных с Византией в реальной переписке, сохранившейся в дичном архиве Каверина, и в романе, а также на других источниках, которыми пользовался писатель, мы надеемся показать, что византийский мотив в романе не только не заимствован Кавериным из переписки, но почти полностью является продуктом авторской фантазии. В статье также показано, что абстрактный образ Византии хотя и обусловлен во многом идейными настроениями советской интелдигенции 60-х годов, тем не менее оказывается в первую очередь вопиощением автобиографических ассоциаций. 
Ключевые слова

образ Византии, прототип, русская советская литература, история идей, русская эмиграция, обращение к христианству

\section{Abstract}

Veniamin Kaverin's novel In Front of the Mirror, which was published in 1972, is based on the actual correspondence between the Soviet mathematician Pavel Bezsonov and the painter Lidia Nikanorova, which Bezsonov handed over to the writer. It is clear even from a superficial comparison that there is a large discrepancy between the source material and the text of the novel; moreover, it is evident upon a closer view that descriptive and ideological features that are connected with Christianity and Byzantium in the novel are close to the ideas and imagery that were typical for Kaverin's contemporaries. From the perspective of the comparison between the text of the correspondence and the novel's text, this paper attempts to show that the image of Byzantium in the novel is not similar to its image in the correspondence. Through an analysis of metaphors, images, and ideas connected with Byzantium in these texts, I intend to show that the image of Byzantium in the novel In Front of the Mirror is not only determined by the public sentiment of this period, specifically, by the second wave of the Soviet intelligentsia's conversion to Christianity, but that it is also extremely personal and based on autobiographical experience.

\section{Keywords}

image of Byzantium, prototype, Soviet Russian literature, history of ideas, Russian emigration, the conversion to Christianity

\section{|}

В архиве Вениамина Александровича Каверина хранится огромное количество материалов, собранных им для своих произведений: письма, воспоминания, протоколы, автобиографии. В “Очерке работы” Каверин сам отмечает за собой склонность к документальной работе: “В юности, занимаясь древней русской литературой, я проводил целые дни в архивах, и с тех пор чувство острого интереса к тайне неопубликованной рукописи не покидало меня” [КАВЕРин 1999: 23]. В 1962 году математик Павел Безсонов передал Каверину свою переписку с художницей Лидией Никаноровой, эмигрировавшей сначала в Константинополь, а затем в Париж. Спустя год Каверин приступает к работе с этими письмами, которые потом лягут в основу романа “Перед зеркалом”, опубликованного в 1972 г. В послесловии нарратор говорит, что дополнил письма только тем, что узнал о Никаноровой и Безсонове в процессе подготовки текста, и несколькими сценами, “пользуясь правом романиста” [IDEM 1982: 307]. Однако в самом ли деле “право романиста” ограничилось несколькими сценами? Ниже мы сравним тот образ Византии, который встает на страницах книги, с тем, что существует в реальной переписке, попавшей в 
руки Каверина, и, исходя из этого, попробуем понять, какое представление о Византии хотел Каверин создать у своего читателя.

Исследователи обращались к роману “Перед зеркалом" неоднократно. Так, Э. Я. Фесенко анализирует образ Лизы Тураевой как образ Художника и романтического персонажа, для которого важна идея двоемирия, выявляя в ее творческих взглядах отражение взглядов самого автора [ФЕСЕНКо 2006: 86]. Проблеме эКфрасиса в романе посвящены несколько работ Е. А. Постниковой [2011А; ЕADEм 2011Б], однако она не анализирует описания произведений византийского искусства, которым в романе отведена немаловажная роль. В. Н. ТумАРь [2009] рассматривает персонажей романа, сопоставляя их с прототипами. С этой же целью обращаются к роману Б. Б. Попова и М. В. Ломовская, при этом в основном фокусе их исследования оказываются именно реальные исторические персонажи, а не герои романа [ПоповА 2009; ЛомовскАя 2011]. М. В. Ломовская опубликовала часть писем Никаноровой к Безсонову, прокомментировав их [EADEM 2016]. При том что исследователи, как правило, отмечают интерес Лизы (и ее прототипа) к византийскому искусству, никто не останавливался специально на изучении образа Византии у Лизы Тураевой или у Лидии Никаноровой. Нет и специальных работ, которые бы касались представлений о Византии как в русской эмиграции начала и середины XX века, так и у самого Каверина.

Роман “Перед зеркалом" написан в редком для XX века жанре эпистолярного романа и рассказывает о любви Лизы Тураевой и Кости Карновского. Познакомившись на гимназическом балу, герои за всю жизнь встречаются всего несколько раз, однако переписку ведут почти всю жизнь. В 1920 г. Лиза уезжает в Константинополь с надеждой попасть в Париж, где она оказывается только в 1923 г. Находясь в Константинополе, она много работает над эскизами византийских мозаик. Однако увлечение ее византийским искусством начинается еще до Константинополя: уже в Петрограде она читает книги по византийскому искусству, посещает лекции византиниста Ф. И. Успенского, увлекается иконописным началом в современной живописи. Интересно, что увлечение героини Византией - единственная черта, которая выделена Кавериным, когда он описывает свою работу над романом. Более того, он не только отмечает в ней эту черту, но еще и ассоциирует ее со своим личным опытом: “Я вспомнил, что образ Византии впервые возник передо мной очень давно, в начале двадцатых годов, когда я был студентом Ленинградского университета" [КАВеРИн 1999: 25]. Учитывая, что, как замечает Э. Я. Фесенко, “автобиографизм и автопсихологизм - неотъемлемые качества поэтики В. Каверина” [ФЕСЕнко 2006: 86], а особенно то, что Лиза - в первую очередь творческий человек, чьи взгляды 
на искусство сближаются со взглядами автора, можно сделать вывод, что автор отводил Византии важную роль.

Значение Византии меняется для художницы в разные периоды ее жизни. Впервые образ Византии появляется в романе не в письмах, а в авторской ремарке [КАВЕРИн 1982: 68-69]: Лиза слушает лекцию профессора-византиниста Ф. И. Успенского [БАСАРгинА 1995: 52] в Петроградском университете. Византия здесь - нечто очень неопределенное, размытое, построенное скорее на ощущениях, чем на конкретных образах.

Позднее с Византией героиня сравнивает и Ялту, попранную немцами; немцы сопоставляются с иноверцами, погубившими империю. В захваченной немцами Ялте Византия впервые станет для Лизы “вечным искусством”, “Источником Духа” и символом ухода от реальности [КАВЕРИн 1982: 111]. Бо́льшая часть размышлений о Византии приходится на пребывание Лизы в Константинополе. Общая черта немцев и турок состоит, по ее мнению, в том, что они не ценят искусство и находятся на низком культурном уровне: турки плохи тем, что изуродовали Святую Софию, превратив ее в мечеть, и тем, что не дают возможности художникам работать с византийскими мозаиками в мечетях.

Современная Турция противопоставлена былой Византии по уровню развития искусства и культуры: “мертвое, необыкновенное” [КАвЕРин 1982: 115] искусство Византии противостоит полному отсутствию искусства турецкого; пестрота и суета стамбульских рынков - вечным развалинам древнего Константинополя, скрытого за ними. Символ этого противостояния - Кахрие-Джами, византийская церковь Хора, где почти полностью сохранились мозаики XIV в. [UNDERWOOD 1967]; здесь властвуют тишина, строгость и глубина, тогда как пространство города связано с суетой, пестротой и поверхностными ощущениями.

Для главной героини Византия - уход, с одной стороны, и поиск с другой. Своей противопоставленностью современности Византия заставляет Лизу отвлекаться от жуткой реальности, которая ее окружает. При этом уход в живопись осмысляется ею как религиозное служение и сопоставляется с подвижничеством: произведения византийского искусства становятся для героини способом совершенствовать свою изобразительную технику.

После переезда Лизы в Париж для нее снижается важность Византии как духовного символа, но резко увеличивается ее художественное значение.

Первое упоминание Византии в Лизиных письмах - это впечатление от глаз на иконах из книги французского византиниста Шарля Диля [WIRTH 1974]: Лизу поражают “широко открытые глаза, эти танцующие фигуры, эти дивные, как бы неловкие позы, эти ломающиеся складки 
одежды на длинных телах" [КАВЕРин 1982: 83]. Постепенно из этого конкретного визуального образа Византия становится абстрактным концептом, набором идей, которые оказываются частью внутренних исканий художницы. Даже когда Лиза обращается к византийскому искусству для того, чтобы найти в этой живописи нечто новое для себя, она никогда не имеет ввиду простое подражание технике или стилизацию - но еще и духовное переосмысление искусства, в противоположность одному из своих возлюбленных - художнику Гордееву, который понимает обращение к византийским образцам как техническую имитацию [IBID.: 154].

В Париже Лиза заканчивает серию картин, связанных с Византией. С этого времени о Византии она говорит чаще всего в связи с ними и называет их “моя Византия” [КАвЕРин 1982: 148, 150, 162, 218]. Теперь “ее Византия” окончательно отрывается от своей исторической реальности и становится исключительно совокупностью некоторых личных впечатлений героини, ее собственным опытом работы с византийским искусством и тем отпечатком, который оно оставило в ее работах. При этом Лиза сама до конца не знает, что стоит за этим образом. Так, например, она пишет Карновскому, что Матисс угадал в ее картинах на выставке следы Византии, хотя она до его замечания их там не видела [IBID.: 218]. Если собрать воедино понятия, которые связываются с этой субъективной “Византией”, то получится, что главные ее черты - это изломанность форм, неестественность изгибов и линий, отвлеченность от современности, одухотворенность (или религиозность), строгость, чистота и печаль. "Византия" - это нечто отвлеченное и абстрактное, однако облеченное в определенные визуальные образы. Цветовая гамма Византии в романе - это теплые цвета, связанные со светом и горящими свечами, самый часто упоминаемый из этих цветов - золотой. Основная характеристика красок византийских произведений искусства для Лизы - невозможность их определить, их оттеночность, неоднозначность, недаром автор пользуется эпитетом мериающий для их описания.

\section{$\|$}

В “Очерке работы” Каверин замечает, что профессор Р., то есть Безсонов, привез ему три подшивки писем художницы Лидии Андреевны Никаноровой, с которой он вел переписку. Позднее Безсонов однажды приезжал к нему, так как Каверин просил его рассказать, что он знал о Никаноровой, а затем сам Каверин был у Безсонова, поскольку хотел посмотреть ее картины [КАВЕРИн 1999: 23]. Однако в фонде Каверина в Российском государственном архиве литературы и искусства (далее РГАЛИ) нет писем Никаноровой 1914-1925 гг. - как раз того времени, 
которое она провела в Ялте и Константинополе. Там, однако, хранятся письма Безсонова 1921-1928 гг., то есть они частично покрывают тот период, когда отсутствуют письма Никаноровой, а также письма 19201922 гг. к Безсонову драматурга С. А. Найденова ${ }^{1}$, с которым художница поддерживала тесные отношения в Ялте [РГАЛИ-1]. Можно было бы предположить, что письма самой Никаноровой имелись у Каверина, а впоследствии были утеряны или уничтожены, но не меньше оснований подозревать, что Каверин в своем автобиографическом рассказе несколько исказил факты. Во-первых, поскольку писатель не упоминает о том, чтобы Безсонов передавал ему какие-то письма позднее, то очень вероятно, что три разные подшивки и есть письма трем разным адресатам: Безсонову, Найденову и Никаноровой. На письмах 1926-1935 гг. сохранился титульный лист, на котором написано: “Часть III” [РГАЛИ-2: 29]. Тем самым вполне логично предположить, что письма хранились в архиве Каверина в едином деле. Первая часть - письма Никаноровой до 1914 г., вторая часть - письма Безсонова к Никаноровой и, наконец, третья - письма Никаноровой с 1926 по 1935 г. При формировании фонда в РГАЛИ они были распределены по персоналиям: письма Никаноровой были помещены в одно дело, а письма Безсонова - в другое. Еще один аргумент в пользу этой гипотезы связан с тем, что та часть романа, которая охватывает период, не задокументированный письмами Никаноровой, отличается от всего остального текста: именно здесь письма Лизы Тураевой максимально полно отвечают на реальные письма Безсонова к Никаноровой. Каверин весьма последовательно идет за текстом реальных писем Безсонова, на их основе выстраивая возможные ответные письма Никаноровой, тогда как на протяжении всего остального романа автор очень вольно обходится с текстом писем. Вполне возможно, это связано с тем, что Каверин сам сочинял письма Лизы Тураевой, опираясь на ответы Безсонова, тогда как готовые письма требовали бы более трудоемкой работы по их переосмыслению и большего их редактирования для соответствия авторскому замыслу.

Обозначив круг архивных источников Каверина, можно перейти непосредственно к их анализу и сопоставлению с романом. Каверин писал, что во время работы над романом “Перед зеркалом” на его рабочем столе “появились книги, и в частности о византийском искусстве, которым занималась моя героиня" [КАвЕРин 1999: 25]. В этом замечании стоит обратить внимание на две вещи. Во-первых, из всех увлечений Никаноровой искусством Каверин упоминает именно о Византии. Вовторых, стоит остановиться на том, какие книги это могли быть: какие книги упоминает Никанорова в письмах, а какие - Каверин в романе.

1 О нем см.: [КАЗАКОВА, ЛитВИНОВА 1999]. 
Книга Диля о Византии, которую прочла Лиза и которая поразила ее репродукциями [КАВЕРИн 1982: 83], ни разу не упоминается в письмах Никаноровой. С другой стороны, сама она в письмах неоднократно упоминает историка европейского средневекового искусства П. П. Муратова: “Это, конечно, 15 лет тому назад написанное, но оно совершенно устарело. Он даст тебе полное понятие о школах" [РГАЛИ-2: 46]. Никаноровой важна та часть византийского искусства, которая находится в Италии, и вообще итальянское искусство, Каверину же интереснее связь Византии с Русью.

Положение Никаноровой в научной среде рисуется из ее переписки тоже совсем иным, чем у героини Каверина. Никанорова - часть французского ученого цеха. Так, французский византинист Габриэль Милле неоднократно предлагает ей делать доклад в рамках курсов, посвященных Византии, которые он ведет в Сорбонне [РГАЛИ-2: 99]. Каверин лишает свою героиню этой части биографии, видимо, чтобы усилить ощущение ее одиночества и ненужности за границей.

Что реальная Никанорова думала и чувствовала в Стамбуле - нам не дано узнать. В сохранившейся части своей корреспонденции она впервые затрагивает византийскую тему, описывая выставку средневекового искусства в Париже [РГАЛИ-2: 32]. Упоминание об этой выставке есть и в книге, но там ей посвящен один небольшой абзац [КАВЕРин 1982: 190-191], где не сказано ничего о том, что там были произведения византийского искусства, тогда как реальная Никанорова в своем письме дает довольно подробный отчет об этой выставке [РГАЛИ-2: 32-33], акцентируя внимание не на своих эмоциональных впечатлениях, а на деталях, важных с точки зрения искусствоведения. При этом средневековье для Никаноровой оказывается неким единым “церковно-рыцарск[им] средневековье[м]”, частью которого является Византия, а византийское искусство, в свою очередь, неотделимо для нее от античной традиции [IBID.: 32]. При этом если для Лизы “византийское искусство” представляет собой некоторое неделимое целое с набором постоянных характеристик, то Никанорова разбивает византийскую живопись на определенные периоды и каждый из них представляет по-разному. Периодизация материала - не единственное, в чем Никанорова демонстрирует научный, рассудочный подход к византийскому искусству. В одном из писем она последовательно излагает концепцию о трех расцветах византийского искусства и об их чередовании с периодами упадка. Именно эта концепция, согласно Муратову, в это время являлась общим местом в тогдашней византинистике, и именно над ней среди прочего работали Милле и Диль [МурАтов 2000: 170]. Подробно Никанорова останавливается только на первом периоде расцвета, для которого, по ее мнению, 
характерны “утонченный вкус и сложная техника, богатство красок, заимствование у Востока” [РГАЛИ-2: 185]. Остальные периоды расцвета она не описывает, зато включает эту периодизацию в исторический контекст. Такой подход полностью противоположен тому, который мы видим у героини романа.

Когда Никанорова описывает еще одну византийскую выставку, проходящую в Париже, то мельком касается и отношения к Византии в обществе, и проблем ее изучения. Она пишет:

Археологические исследования все более подтверждают и освобождают от предрассудков, что это искусство не “мертвое”, повторяемое на протяжении тысячелетия. Теперь уже всем ясно, что это искусство имело свою жизнь, временами пышную и упадочную [РГАЛИ-2: 185].

Очевидно, что эта ровно та проблема, которая волнует Муратова в статье “Византийская живопись”: “Немудрено, что история византийской живописи была до сих пор всегда скорее теорией византийской живописи, менявшейся смотря по тем умозаключениям, для коих давало повод наличие известных ее памятников” [МурАтов 2000: 155]. Никанорову волнуют не только проблемы современного византиноведения, но и общественное отношение к Византии. Так, в 1931 г. она отмечает, что интерес к Византии возрастает, а до этого она же сетует на то, что русских совсем не интересует изучение Византии [РГАЛИ-2: 185].

Иным оказывается и отношение Никаноровой к Турции. Она не испытывает отвращения ни к самим туркам, ни к турецкому как чему-то, что противостоит византийской культуре. Когда она думает об изменениях, произошедших в Турции вследствие преобразований Ататюрка, она даже сожалеет о том, что Константинополь потерял свой колоритный облик. Противопоставление обыденной современности и сакральной древности ей чуждо.

Что же касается важных для романа религиозных мотивов, то оказывается, что в письмах Никаноровой они очень редки, зато довольно много их в письмах Безсонова и Найденова, но нигде не просматривается их связи с Византией. Вместо христианских метафор, которых в романе очень много, в письмах оказываются античные сравнения и представление о судьбе как о роке (например: “У меня есть любимое дело, я люблю, любима, у меня есть прекрасная дружба [. . .] Нет, мне страшно! Боги завистливы” [РГАЛИ-2: 150]), что исключает ассоциации с Византией. Нет здесь и сравнений с образами святых. В романе Лиза может сравнивать реальных людей с иконописными ликами [КАВЕРин 1982: $130,138]$, но в письмах ничего подобного нет: все это оказывается изобретением Каверина. 
В романе “Перед зеркалом" христианская эстетика выражена в описании богослужения (детское воспоминание Лизы [КАВеРИН 1982: 72]) и в религиозной живописи, то есть именно в том, в чем, например, Безсонов отрицает ее:

В христианстве есть свой эстетизм. И конечно, это не тот эстетизм, который в пасхальную заутреню влечет в церковь смотреть на трогательно напряженные лица девушек, когда они освещены дрожащим светом свечи, глаза углубляются, а нежные тона одежд оттеняют цвет кожи. И это не тот, что дал величайшее создание христианских художников, по существу язычников [РГАЛИ3: 98].

“Дрожащий свет”, внимание к цветам, акцент на глазах - все это сближает этот пассаж из письма с романным описанием службы, которую вспоминает Лиза, но только с одним отличием: с точки зрения Каверина и вопреки Безсонову, в этом и заключена сущность христианской эстетики.

Отсутствует в письмах и мотив ухода от реальности. В отличие от романа, где Лиза окружена страданием, единственными просветами в котором ей представляются Костя и живопись, письма Никаноровой не пропитаны страданием, даже наоборот - они в большинстве своем счастливые. В романе героиня осмысляет свой уход в живопись как подвижничество (мотив ухода от реальности Каверин заимствует из письма Безсонова к Никаноровой [РГАЛИ-3: 31]), но сама Никанорова в таких понятиях о себе не мыслит. Вообще церковная атрибутика в письмах никаким сакральным ореолом не обладает, так что описания ликов на иконах и сцены богослужения полностью придуманы самим КАВЕРИным [1982: 72, 130, 138]. Для него образ монастыря связан с мудростью, строгостью, это образ возвышенный и важный [IBID.: 109], Никанорова же и Безсонов иногда позволяют себе иронизировать над религиозными атрибутами и чувствами. На примере эпизодов, которые Каверин очень близко к тексту переносит из писем в роман [IBID.: 166, 252], можно заметить, что писатель убирает иронию и комизм из изображения религиозных реалий. Один из таких эпизодов - это описание Лизой предпасхальной процессии на Корсике: Никанорова с комизмом описывает вид этой процессии в дневное время [РГАЛИ-2: 158], в романе же комичных черт в этой сцене вовсе нет.

Роль Византии в творчестве Никаноровой - исключительно техническая, а не метафизическая, как для Тураевой. Каверин представляет свою героиню ищущей что-то неуловимое, нечто, что нельзя передать словами, тогда как творческий поиск подлинной Никаноровой связан с техникой. Невнимание к технике в современных ей живописных течениях она воспринимает негативно [РГАЛИ-2: 61, 181]. 
География византийского мира для Никаноровой шире и подробней, чем для Тураевой. Для Лизы вся Византия сосредоточена в Константинополе, даже скорее в одном из его храмов - Кахрие-Джами (совсем редко она вспоминает и про Святую Софию [КАвЕРИн 1982: 121, 129], которую за все свое пребывание в городе, видимо, так и не посетила). Никанорова же не ограничивается Константинополем: не менее важные для нее памятники византийского искусства - Мистра [РГАЛИ-2: 182] и особенно Равенна [IBID.].

Италия вообще играет в письмах очень большую роль, тогда как в романе ее почти нет. Эта страна для Никаноровой оказывается не менее (если не более) важной, чем Франция. Из Константинополя она хочет уехать именно в Италию, но это у нее не выходит, и тогда она отправляется в Париж в надежде попасть в Италию оттуда. Идеи пути художницы, выстроенного в романе (из России в Париж через Константинополь), в письмах нет. Константинополь не является здесь ступенью между Россией и Парижем на пути в искусстве. Похожую, однако, схему предлагает Безсонов:

С. А. [Найденов] мне написал, что ты устремилась в Италию, а ты пишешь в Париж. Первое значит увлечение классицизмом, самое большее - эпохой Возрождения, второе - светом французских просветителей. Конечно, м. б. самое мудрое через Италию в Париж [РГАЛИ-3: 1].

Эту идею аллегоризации творческого пути в непосредственном географическом выражении, предложенную Безсоновым, Каверин сделает в романе одной из смыслообразующих. Однако он характерным образом изменяет опорную точку: на месте Италии и эпохи Возрождения оказывается Константинополь как символ византийского искусства и вообе Византии. Кроме того, в письмах выстраивается и иная схема преемственности. Если в романе Каверин акцентирует внимание на том, что русское искусство наследует Византии, то Никанорова об этом ничего не пишет, зато отражение византийской традиции в западном искусстве для нее очень важно [РГАЛИ-2: 32, 33]. Привнесенная Кавериным идея о связи Византии и России призвана подчеркнуть ностальгию героини, которой совсем нет в письмах прототипа Тураевой: о сильной тоске по родине Никанорова впервые пишет Безсонову только в 1935 г., в одном из последних писем [IBID.: 205].

Взгляд Лидии Никаноровой на Византию - взгляд исследователя. Ей важен исторический контекст, периодизация византийского искусства, она включена в работу византинистов во Франции, Византия же в ее переписке с Безсоновом - это прежде всего период в истории искусства, исторический факт. Такой образ не отвечал художественным задачам 
Каверина, такая Византия не могла быть “зеркалом”, отражающим творческие и религиозные искания главной героини. В романе мы видим совсем иной образ Византии, главной чертой которого становится противопоставленность повседневной жизни и сакральность. Этот образ тесно сопряжен с христианством и Россией.

Обращение Каверина к Византии, а также связь между Византией и христианством в романе можно объяснить настроениями советской интеллигенции во время его написания. Важность христианской образности, древней иконописной русской и византийской традиции встраивается в контекст возрастающего интереса к христианству в 1960-70-х гг. [АвеРИнцев 2002].

Наконец, Византия для Каверина - это еще и важный автобиографический образ. В романе Лиза впервые слышит о Византии на лекции Ф. И. Успенского. При этом в “Очерке работы” Каверин пишет, что и у него образ Византии впервые возник в Петроградском университете [КАВЕрин 1999: 25]. Скорее всего, он сам бывал на лекциях Ф. И. Успенского, так как они одновременно находились в университете: Каверин закончил историко-филологический факультет в 1924 г., а Успенский преподавал там с 1922 до 1927 г. [ЖЕБЕЛЕв 1929: 3], тогда как Никанорова не могла слушать его лекций, поскольку к 1922 г. была уже в эмиграции. В итоге такой, какой мы видим Византию в книге Каверина: сакральной, одухотворенной, абстрактной, - она представлялась не только современникам Каверина, но и ему самому.

\section{Библиограсрия}

\section{Издания источников}

КАВЕРИН 1982

КАВеРин В. А., “Перед зеркалом. Роман в письмах", in: IDEм, Собрание сочинений, 6, Москва, 1982, 5-258. 1999

КАВЕРИн В. А., “Очерк работы”, in: IDEм, Очерк работы. Открытая книга. Литературные заметки. Избранные письма, Москва, 1999, 5-30.

\section{Архивные материалы}

РГАЛИ-1

РГАЛИ, Ф. 1501, ОП. 2, Д. 466.

РГАЛИ-2

РГАЛИ, Ф. 1501, ОП. 2, Д. 467.

РГАЛИ-3

РГАЛИ, Ф. 1501, ОП. 2, Д. 464. 


\section{Литература}

\section{АВЕРИНЦЕВ 2002}

АвеРинцев С. С., “Обращение к Богу советской интеллигенции в 60-70-е годы”, Община ХХІ век, 9 (21), сентябрь, 2002.

БАСАРГИНА 1995

БАСАРГИНА Е. Ю., “Ф. И. УсПеНСКИЙ: обЗор личНого фонда”, in: И. П. МЕДВЕДЕВ, ред., Архивы русских византинистов, С.-Петербург, 1995, 45-57.

\section{ЖЕБЕЛЕв 1929}

ЖЕБеЛЕв С. А., “Федор Иванович Успенский. І. Биографическая канва”, in: IDEM, ред., Памяти академика Федора Ивановича Успенского (1848-1928), Ленинград, 1929, 1-3.

КАЗАКОВА, ЛИТВИНОВА 1999

КАЗАКОвА Н. А., ЛитвиновА Л. С., “Найдёнов”, in: П. А. Николаев, ред., Русские писатели (1800-1917): Биографический словарь, 4: М-П, Москва, 1999, 222-225.

ЛОМОВСКАЯ 2011

ЛомовскАя М. В., “Герои Каверина в романе и в жизни”, Звезда, 8, 2011, 124-155. 2016

ЛомовскАя М. В., подгот., коммент., “Это одно из «самого хорошего» в моей жизни. .. : Письма Лидии Никаноровой Павлу Безсонову из Франции в Россию (1925-1935)”, Звезда, 5, 2016, 151-209.

Муратов 2000

МУРАТов П. П., “Византийская живопись”, in: IDEM, Ночные мысли, Москва, 2000, 152-173.

ПоПовА 2009

ПоповА Б. Б., “«Подняться над этим счастьем»: Страница истории русского зарубежья”, Русское искусство, 4, 2009, 152-159.

ПостНова 2011A

Постникова Е. А., “Пейзаж в романе В. Каверина «Перед зеркалом»”, Вестник

Ленинградского государственного университета им. А. С. Пушкина, 1/1, 2011, 50-58. 2011ь

ПостновА Е. А., “Портрет в романе В. Каверина «Перед зеркалом»”, Вестник Вятского государственного университета, 2-2, 2011, 109-113.

ТумАРь 2009

ТумАРь В. Н., “Прототипика героев романа В. Каверина «Перед зеркалом»”, in: Центральная городская библиотека г. Нижнего Новгорода [официальный сайт], [2009] (http://www.gorbibl.nnov.ru/kaverin; последнее обращение: 25.08.2017).

ФЕСЕНКо 2006

ФЕсенко Э. Я., ХУдожественная концепщия личности в произведениях В. А. Каверина, Москва, 2006.

UNDERWOOD 1967

Underwood P. A., The Kariye Djami, 3: The Frescoes, Bollingen, 1967.

WIRTH 1974

WiRTh P., "Diehl, Charles Michel," in: Biographisches Lexikon zur Geschichte Südosteuropas, 1, München, 1974, 397-398.

\section{References}

Averintsev S. S., "Obrashchenie k Bogu sovetskoi intelligentsii v 60-70-e gody," Obshchina XXI Vek, 9 (21), September, 2002.
Basargina E. Yu., "F. I. Uspenskii: obzor lichnogo fonda," in: I. P. Medvedev, ed., Arkhivy russkikh vizantinistov, St. Petersburg, 1995, 45-57. 
Fesenko E. Ya., Khudozhestvennaia kontseptsiia lichnosti v proizvedeniiakh V. A. Kaverina, Moscow, 2006.

Kazakova N. A., Litvinova L. S., "Naidenov," in: P. A. Nikolaev, ed., Russkie pisateli (1800-1917): Biograficheskii slovar', 4, Moscow, 1999, 222-225.

Lomovskaya M. V., "Geroi Kaverina v romane i v zhizni,” Zvezda, 8, 2011, 124-155.

Lomovskaya M. V., "Eto odno iz 'samogo khoroshego' v moei zhizni. . . : Pis'ma Lidii Nikanorovoi Pavlu Bezsonovu iz Frantsii v Rossiiu (1925-1935)," Zvezda, 5, 2016, 151-209.

Muratov P. P., Nochnye mysli, Moscow, 2000.

Popova B. B., “'Podniat'sia nad etim schast'em': Stranitsa istorii russkogo zarubezh'ia," Russkoe iskusstvo, 4, 2009, 152-159.

Postnova E. A., "Landscape in the Novel by V. Kaverin Before the Mirror," Vestnik of Pushkin Leningrad State University, 1/1, 2011, 50-58.
Postnova E. A., "Portrait in V. Kaverin's Novel Before the Mirror," Herald of Vyatka State University of Humanities, 2-2, 2011, 109-113.

Tumar' V. N., "Prototipika geroev romana V. Kaverina 'Pered zerkalom'," in: Central City Library of Nizhny Novgorod [official website], [2009] (http://www.gorbibl.nnov.ru/kaverin; last access: 25.08.2017).

Underwood P. A., The Kariye Djami, 3: The Frescoes, Bollingen, 1967.

Wirth P., "Diehl, Charles Michel," in: Biographisches Lexikon zur Geschichte Südosteuropas, 1, München, 1974, 397-398.

Zhebelev S. A., "Fedor Ivanovich Uspenskii. I. Biograficheskaia kanva," in: Pamiati akademika Fedora Ivanovicha Uspenskogo (1848-1928), Leningrad, 1929, 1-3.

Ася Вадимовна Кулакова, бакалавр филологии

Национальный исследовательский университет “Высшая школа экономики”, магистрант факультета гуманитарных наук

105066 Москва, ул. Старая Басманная, д. 21/4, стр. 1

Россия/Russia

a.cula@mail.ru

Received September 29, 2016 